\title{
The influence of toothbrushing and coffee staining on different composite surface coatings
}

\author{
Brigitte Zimmerli • Tamara Koch • Simon Flury • \\ Adrian Lussi
}

Received: 29 March 2010 / Accepted: 4 February 2011 /Published online: 18 February 2011

(C) Springer-Verlag 2011

\begin{abstract}
The aim of our study is to evaluate the performance of surface sealants and conventional polishing after ageing procedures. Eighty circular composite restorations were performed on extracted human molars. After standardised roughening, the restorations were either sealed with one of three surface sealants (Lasting Touch (LT), BisCover LV (BC), G-Coat Plus (GP) or a dentin adhesive Heliobond (HB)) or were manually polished with silicon polishers (MP) $(n=16)$. The average roughness $(\mathrm{Ra})$ and colourimetric parameters $(\mathrm{CP})\left(\mathrm{L}^{*} \mathrm{a}^{*} \mathrm{~b}^{*}\right)$ were evaluated. The specimens underwent an artificial ageing process by thermocycling, staining (coffee) and abrasive (toothbrushing) procedures. After each ageing step, $\mathrm{Ra}$ and $\mathrm{CP}$ measurements were repeated. A qualitative surface analysis was performed with SEM. The differences between the test groups regarding Ra and $\mathrm{CP}$ values were analysed with nonparametric ANOVA analysis $(\alpha=0.05)$. The lowest $\mathrm{Ra}$ values were achieved with HB. BC and GP resulted in Ra values below $0.2 \mu \mathrm{m}$ (clinically relevant threshold), whereas LT and MP sometimes led to higher Ra values. LT showed a significantly higher discolouration after the first coffee staining, but this was normalised to the other groups after toothbrushing. The differences between the measurements and test groups for Ra and $\mathrm{CP}$ were statistically significant. However, the final colour difference showed no statistical difference among the five groups. SEM evaluation showed clear alterations after ageing in all coating groups. Surface sealants and dentin adhesives have the potential to reduce surface roughness but
\end{abstract}

\footnotetext{
B. Zimmerli $(\bowtie) \cdot T$. Koch $\cdot$ S. Flury $\cdot$ A. Lussi

Department of Preventive, Restorative and Paediatric Dentistry,

School of Dental Medicine, University of Bern,

Freiburgstrasse 7,

3010 Bern, Switzerland

e-mail: brigitte.zimmerli@zmk.unibe.ch
}

tend to debond over time. Surface sealants can only be recommended for polishing provisional restorations.

Keywords Surface sealant · Roughness · Staining · Composite finishing

\section{Introduction}

Restorations with smooth surfaces are important to inhibit plaque accumulation [1-3]. The critical surface roughness for bacterial retention was proven to be a mean roughness (Ra) of $0.2 \mu \mathrm{m}[4,5]$. Evaluations with patients showed that people recognise differences of surface roughness between Ra 0.25 and $0.5 \mu \mathrm{m}$ with their tongues [6]. Thus, a smooth surface is also important for patient comfort. Furthermore, rough surfaces tend to discolour faster, which is an aesthetic problem [7].

However, finishing and polishing procedures are a time consuming step in dental practice. First, surface sealants were developed for provisional restorations. An application of surface sealant on provisional restorations results in significantly less bacterial adhesion [8]. Furthermore, the polishing time required to obtain a glossy and smooth appearance can be reduced.

Therefore, it was of interest to use surface sealants for direct composite restorations. Surface sealants minimise microleakages at the restoration margins and ensure a lustrous surface $[9,10]$. The capacity of surface sealants to mask surface defects of resin composites and to provide a more uniform and regular surface has been observed in several studies [11-13]. It has been shown that the application of a surface sealant results in an improvement of the surface texture $[11,12,14]$ and may enhance the interface wear resistance of different cementation techni- 
ques [15]. The coatings improve the tooth's resistance to abrasion and discolouration and therefore maintain the aesthetic appearance [15-19].

On the other hand, it has been shown that the abrasion resistance of restorative materials with filler particles $<1 \mu \mathrm{m}$ could not be improved by surface sealants $[12,16$, 20]. Furthermore, it has been reported that surface sealants are not able to compensate for all surface irregularities [2022]. The effectiveness of those materials depends upon their penetration into the restoration subsurface microstructure before polymerisation is completed, which depends on the viscosity of the material and its ability to wet and spread over an etched surface $[10,19,23]$.

However, there is little information about the long-term integration of surface sealants. As the material properties have been improved, it was of interest to evaluate the performance of available surface sealants after different ageing procedures.

The following hypotheses were tested:

Hypothesis 1: There are no differences between the surface roughness of sealed versus manually polished composite surfaces after their initial application.

Hypothesis 2: There are no differences between the test groups regarding surface roughness after simulated toothbrushing.

Hypothesis 3: There are no differences between the test groups concerning staining susceptibility.

\section{Material and methods}

\section{Specimen preparation}

Extracted human molars were sectioned in a mesiodistal axis with a diamond blade saw (Isomet, low-speed saw; Buehler, Ltd., USA). The buccal and oral surfaces were flattened with silicon carbide paper and were embedded in circular moulds with a self-curing resin (Paladur, Heraeus Kulzer GmbH, Hanau, Germany). Round cavities (diameter, $6 \mathrm{~mm} ; 1.5-\mathrm{mm}$ depth) were prepared in the coronal parts of the teeth. An etch-and-rinse adhesive (Optibond FL, Kerr, Orange, CA, USA) was applied according to the manufacturer's instructions. The cavity was restored with a nanohybrid composite (CeramX mono, shade M2, Dentsply DeTrey, Konstanz, Germany) and light cured with a LED light-curing unit (Bluephase G2, Ivoclar Vivadent, Schaan, Liechtenstein) for $30 \mathrm{~s}$ against a Mylar strip (Universal strips, $0.005 \mathrm{~mm}$; Odus Dental, Dietikon, Switzerland). Light intensity was regularly checked by a radiometer (bluephase meter, Ivoclar Vivadent) and was always $>1,000 \mathrm{~mW} / \mathrm{cm}^{2}$. The composition of the restorative materials is listed in Table 1.
The surface of the specimens was roughened in a standardised manner with 220 grit silicon carbide paper with a force of $10 \mathrm{~N}$ and water cooling (Struers TegraPol15 and TegraForce, Struers, Ballerup, Denmark). A stainless steel bur was used to make two small grooves in the embedding material as reference parallel to the vertical stream pattern resulting from the roughening.

The first measurements (M1) were performed after standardised roughening. The Ra values were determined with a profilometer (Perthometer S2, Mahr, Thalwil, Switzerland). The profilometer was set for a tracing length of $1.75 \mathrm{~mm}$, a cut-off value of $0.25 \mathrm{~mm}$ and a stylus speed of $0.1 \mathrm{~mm} / \mathrm{s}$ (scan force, $0.9 \mathrm{mN}$; stylus radius, $2 \mu \mathrm{m})$. Each specimen was scanned four times: two times along the virtual connection of the two grooves/references and two times perpendicular to this line. Prior to each use, the accuracy of the profilometer was controlled using a roughness standard (Mahr). The colourimetric analyses were performed with VITA Easyshade (Vita Zahnfabrik, Bad Säckingen, Germany). The measurement device was warmed up and calibrated following the manufacturer's instructions. Black paper was selected to maintain a constant background when measuring the specimens. Each measurement was performed three times and the colour parameters were averaged. The colour differences were each calculated to the colour parameters of M1 and M2 (measurement after polishing procedure) using the following equation

$$
\text { [24]: } \Delta E=\sqrt{\left[\left(L_{2}-L_{1}\right)^{2}+\left(a_{2}-a_{1}\right)^{2}+\left(b_{2}-b_{1}\right)^{2}\right]} .
$$

Silicone impressions (President light and regular body, Coltène Whaledent, Altstätten, Switzerland) of the surfaces were made after each measurement period.

The specimens were randomly divided into five groups $(n=16)$. The surfaces of groups one to four were first etched with $35 \%$ phosphoric acid (Ultra-Etch, Ultradent, UT, USA) for $20 \mathrm{~s}$, rinsed with water for $20 \mathrm{~s}$ and then air-dried. One of the three surface sealants or the dental adhesive was then applied, left undisturbed for $15 \mathrm{~s}$ and light-cured for $30 \mathrm{~s}$. The following surface sealants were chosen: group 1, Lasting Touch (LT) (Dentsply DeTrey); group 2, BisCover LV (BC) (Bisco, IL, USA) and group 3, G-Coat Plus (GP) (GC Corporation, Tokyo, Japan). In group 4 , a conventional dentin adhesive (Heliobond (HB), Ivoclar Vivadent) was applied and light-cured (Table 1). Group 5 was manually polished (MP) with diamond burs (diamond bur grit, 40 and $25 \mu \mathrm{m}$; Intensiv, Grancia, Switzerland), silicon carbide polishers (grit, 35-48 and $6 \mu \mathrm{m}$; Shofu, Kyoto, Japan) and Occlubrush (KerrHawe, Bioggio, Switzerland). Each instrument was applied for $5 \mathrm{~s}$ to the surface. The roughness measurements, the colourimetric analysis and the silicone 
Table 1 Composition of the restorative materials

\begin{tabular}{|c|c|c|c|}
\hline Composite & Manufacturer & Type & Composition \\
\hline $\begin{array}{l}\text { CeramX mono shade M2 } \\
(60701322)\end{array}$ & Dentsply DeTrey & $\begin{array}{r}\text { Nanohybrid } \\
\text { composite }\end{array}$ & $\begin{array}{l}\text { Methacrylate-modified polysiloxane, dimethacrylate } \\
\text { resin, fluorescent pigment, camphoroquinone, } \\
\text { ethyl-4(dimethylamino benzoate, pigments, barium } \\
\text { borosilicate glass, methacrylate functionalised silicon } \\
\text { dioxide nanofiller }\end{array}$ \\
\hline \multicolumn{4}{|l|}{ Adhesive } \\
\hline Optibond FL (62890) & Kerr & $\begin{array}{l}\text { Etch-and-rinse } \\
\text { adhesive }\end{array}$ & $\begin{array}{l}\text { Etching: } 37.5 \% \text { phosphoric acid, silica thickener } \\
\text { Primer: HEMA, GPDM, PAMM, ethanol, water, } \\
\text { photoinitiator } \\
\text { Primer: HEMA, GPDM, PAMM, ethanol, water, } \\
\text { photoinitiator } \\
\text { Adhesive: TEG-DMA, UDMA, GPDM, HEMA, } \\
\text { Bis-GMA, filler, } \\
\text { photoinitiator }\end{array}$ \\
\hline Ultra-Etch (B3J2M) & Ultradent & Etchant & $35 \%$ phosphoric acid \\
\hline Heliobond (K04434) & Ivoclar Vivadent & Adhesive & $\begin{array}{l}\text { Bis-GMA, triethylene glycol dimethacrylate, } \\
\text { initiators, stabilisers }\end{array}$ \\
\hline \multicolumn{4}{|l|}{ Surface sealants } \\
\hline Lasting Touch (070502) & Dentsply DeTrey & Surface sealant & $\begin{array}{l}\text { Acetone, urethane-dimethacrylate resin, } \\
\text { butyl alcohol, dipentaerythol } \\
\text { penta acrylate phosphate }\end{array}$ \\
\hline BisCover LV (0700002076) & Bisco & Surface sealant & Dipentaerythriol diacrylate esters, ethanol \\
\hline G-Coat Plus (0707131) & GC corporation & Surface sealant & $\begin{array}{l}\text { Urethane methacrylate, methylmethacrylate, } \\
\text { camphorquinone, silicon dioxide, phosphoric } \\
\text { ester monomers }\end{array}$ \\
\hline
\end{tabular}

impressions of the surfaces were repeated (M2). The measurements were continued after artificial ageing (M3M8) with thermocycling (M3), coffee staining for $24 \mathrm{~h}$ (M4), toothbrushing procedure (20,000 strokes) (M5), coffee staining for $24 \mathrm{~h}$ (M6), toothbrushing (20,000 strokes) (M7) and a repeated toothbrushing with 40,000 strokes (M8) (Fig. 1).

\section{Thermocycling}

The teeth were thermocycled with 5,000 cycles at $55^{\circ} \mathrm{C}$ and $5.5^{\circ} \mathrm{C}$ with a dwell time of $30 \mathrm{~s}$ in each bath and a transfer time of $4 \mathrm{~s}$.

\section{Coffee staining}

In order to simulate coffee staining, a pellicle layer with saliva was formed. Freshly stimulated human saliva (pH 7.1) was collected. The specimens were immersed in the saliva and stored in a shaking water bath (Salvis AG, Reussbühl, Switzerland) at $37^{\circ} \mathrm{C}$ for $2 \mathrm{~h}$. The specimens were then immersed for $24 \mathrm{~h}$ in black coffee in an incubator at $37^{\circ} \mathrm{C}$ (Memmert, Schlierheim, Germany). The coffee (Ristretto, Nespresso, Nestlé, Vevey, Switzerland) was prepared with one capsule of coffee $(10 \mathrm{~g})$ and $40 \mathrm{ml}$ of water in an automatic coffee machine. The $\mathrm{pH}$ of the coffee was 5.25 at nearly $44^{\circ} \mathrm{C}$, when the specimens were added. After each staining section, the specimens were rinsed thoroughly with distilled water.

\section{Toothbrushing}

For simulated toothbrushing, a slurry of toothpaste $(\mathrm{pH}$ 5.64) was prepared by mixing toothpaste (ELMEX Kariesschutz, GABA, Therwil, Switzerland) (RDA 77) with artificial saliva [25] at a 1:3 proportion. Toothpaste slurry (35 ml) was inserted into each reservoir of the device for simulated toothbrushing (Bürstmaschine linear LR1, Syndicad, München, Germany). Plane brush heads with round bristles (Ultra Super Sensitive Zahnbürste, Trisa, Triengen, Switzerland) were applied with a force of $1.8 \mathrm{~N}$. The device made two strokes of horizontal movements per second. Series of 20,000 (M5), 20,000 (M7) and 40,000 strokes (M8) were chosen.

The same toothbrush was reused for all test series for one specimen. The toothpaste slurry was replaced each time. Before the surface of the specimens was measured, the specimens were cleaned under running tap water. 


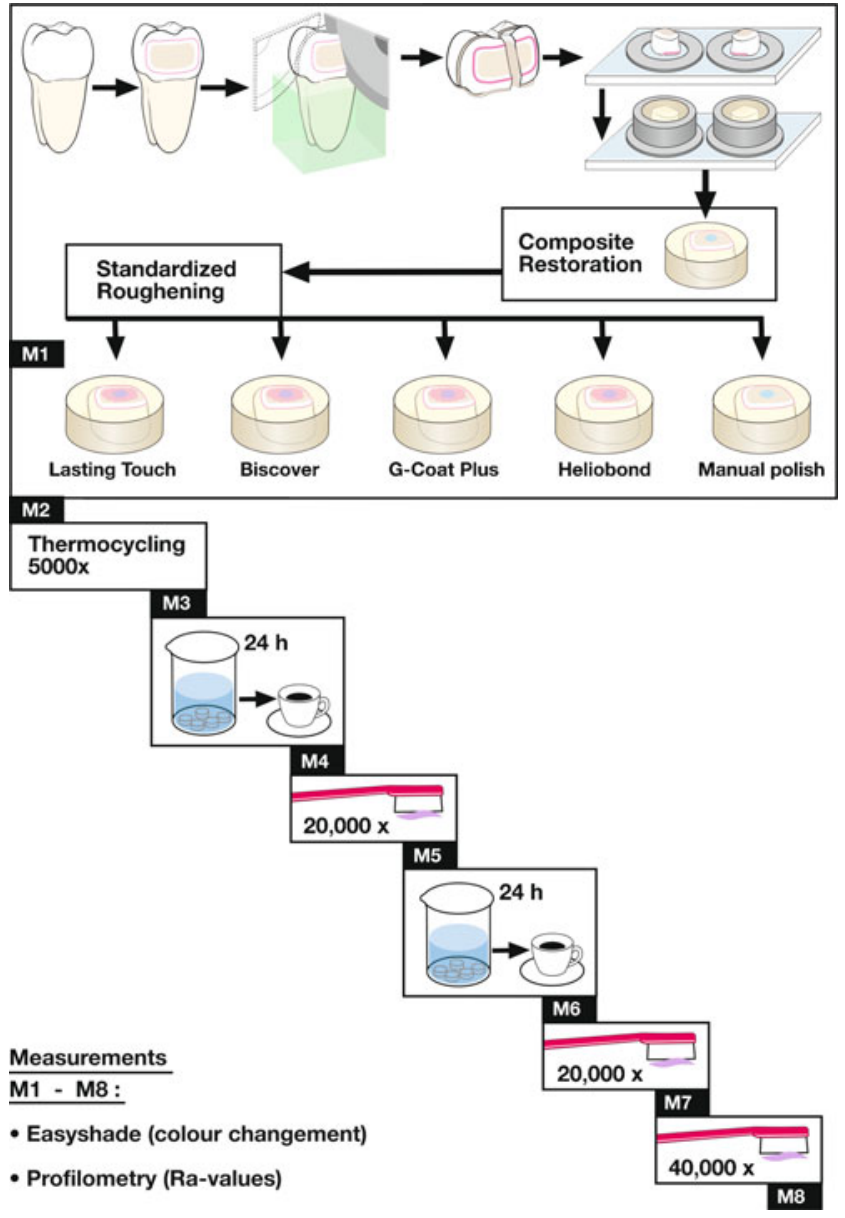

Fig. 1 Set-up of the study with the different measuring points (M1-M8)

\section{Qualitative SEM evaluation}

Replicas of the surface silicone impressions were made with self-curing resin (Epofix, Struers) and then gold/ palladium-coated $(100 \mathrm{~s}, 50 \mathrm{~mA})$ using a sputtering device (Balzers SCD 050; Balzer Union, Balzers, Liechtenstein). The SEM evaluation was performed with a stereoscan S360 scanning microscope at $20 \mathrm{kV}$ (Cambridge Instruments, Cambridge, UK). A digital SEM photomicrograph with $\times 17, \times 100$ and $\times 1,000$ magnification was taken of two representative specimens per group for each of the eight measurements (M1-M8) (Digital Image Processing System, version 2.3.1.0, point electronic $\mathrm{GmbH}$, Halle, Germany).

\section{Statistical analyses}

All comparisons of colourimetric and roughness values were subjected to statistical analyses. Possible differences among the groups (A) and experimental conditions (T), as well the product of their experimental interactions (AT), were investigated using a nonparametric model for longitudinal data (F1_LD_F1 model by Brunner et al. [26]).
The Wilcoxon signed-rank test was applied at the very beginning at baseline (M1) due to possible expected differences among the lengthwise and perpendicular roughness measurements. The level of significance was set at $\alpha=0.05$.

\section{Results}

Surface roughness

A significant difference was observed among the two lengthwise and the two perpendicular roughness measurements, especially at baseline $(p<0.001$, Wilcoxon signedrank test). Therefore, instead of averaging all four values, the two lengthwise $(l)$ and the two perpendicular $(p)$ values were averaged separately. The mean baseline roughness was $0.400 \mu \mathrm{m} \pm 0.131(l)$ and $1.012 \mu \mathrm{m} \pm 0.137(p)$.

The results of the mean roughness of $l$ and $p$ and their change during the course of the polishing and the further ageing procedure are presented in Fig. 2a, b. The surface roughness was significantly improved after the sealant/ adhesive was applied or the conventional manual polishing was performed in all five groups. In groups LT and BC, the longitudinal and the perpendicular measurements were still significantly different, but the difference was not as high as that at baseline. In groups GP, HB and MP, the longitudinal and the perpendicular measurements showed values within the same range. LT showed the highest mean roughness of all tested surface sealants for the longitudinal and perpendicular measurements in M2. It was the only sealant that achieved Ra values above the significant threshold of $0.2 \mu \mathrm{m}$ for bacterial retention. During the experiment, it had a tendency of decreasing surface roughness after the first and second toothbrushing treatments. The mean values for the longitudinal measurement dropped clearly below the critical threshold, while the perpendicular measurement achieved values close to $0.2 \mu \mathrm{m}$. The group that underwent 40,000 brushstrokes showed increased surface roughness. In addition, MP achieved slightly higher Ra values than the threshold of $0.2 \mu \mathrm{m}$, while sealing with $\mathrm{HB}$ resulted in the lowest $\mathrm{Ra}$ values. Ageing of the samples did affect $\mathrm{Ra}$ values. LT showed the highest changes in surface roughness. A nonparametric model for longitudinal data was applied separately for the lengthwise and perpendicular measurements M2-M8 (Table 2). For the lengthwise as well as perpendicular values, the effect of the group (A), the effect of the ageing procedures $(\mathrm{T})$ as well as their interaction (AT) were significant, whereas when comparing the initial polished samples (M2) with the final aged polished samples (M8) only, no differences in roughness values were found. For the lengthwise $(l)$ measurements, A and T were statistically significant $(p<0.05)$, whereas AT showed no differences $(p=0.124)$ when comparing surface 
Fig. 2 a Mean roughness values measured following the roughening axis $(l)$. b Mean roughness values measured perpendicular to the roughening axis $(p)$
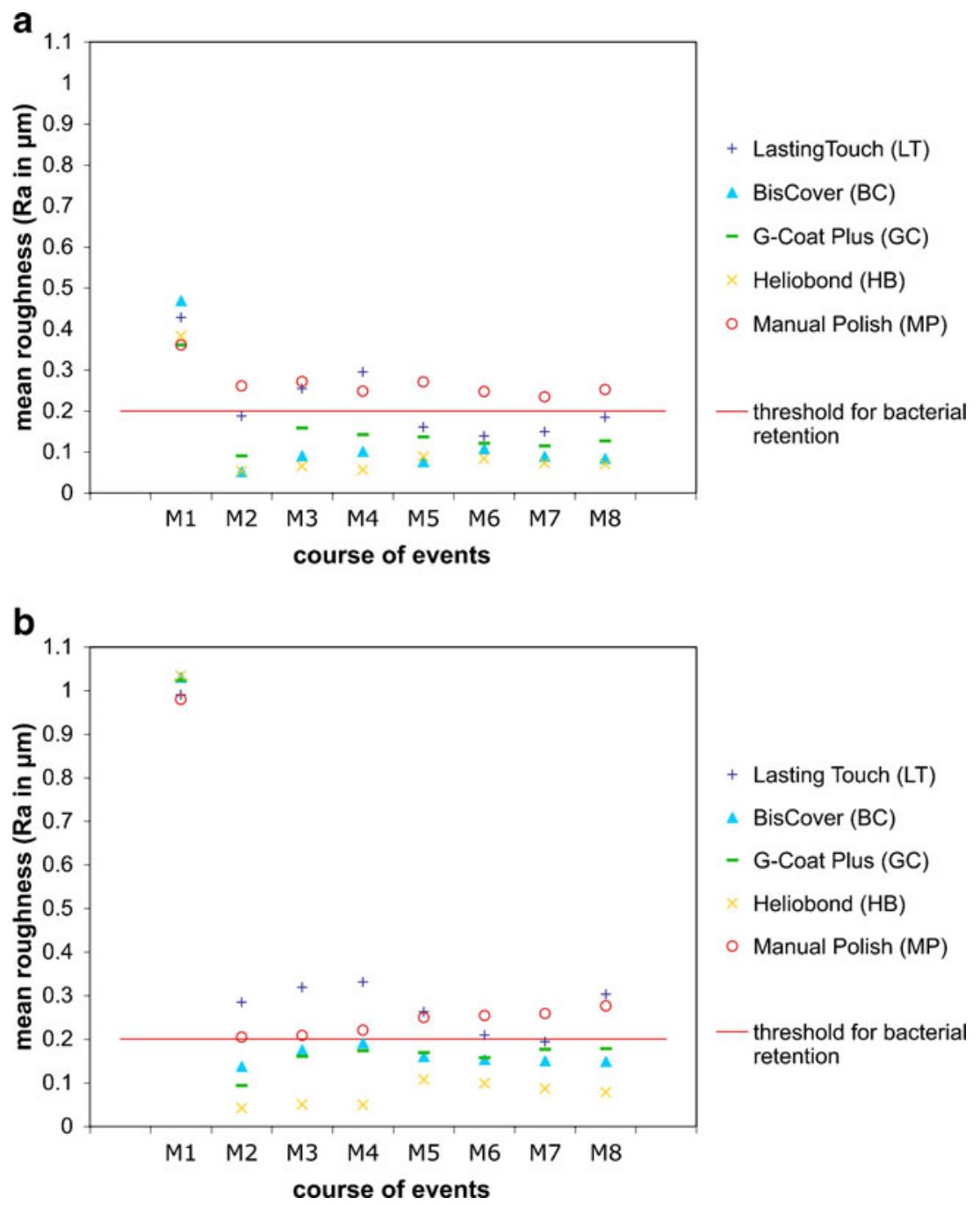

roughness of M8 to M2. For the perpendicular measurements, all parameters were significant $(p<0.05)$.

\section{Colourimetric evaluation}

Significant colour changes were found in the course of the ageing procedures in all five groups. The application of the surface sealant/manual polish and the thermocycling process already had an effect on the colour. This procedure changed the colour about $2.75-4.2 \mathrm{U}$ according to the equation for mean colour changes $\Delta \mathrm{E}$.
Statistically significant colour changes were found between the five groups (A), between the time points M2-M8 (T) and the time behaviour of the groups (AT) (Table 3).

The application of the surface sealant/manual polish resulted in a colour change of about three units in all groups. The first immersion in coffee (M4) influenced the colour change by about five units as compared to M2 (Fig. 3). LT showed a higher colour change of nearly double that amount. The simulated toothbrushing had a partly reversible influence (M5). The colour difference
Table 2 Nonparametric analysis of surface roughness measurements (M2-M8)

$A$ effect of test group, $T$ effect of measurement point, $A T$ interaction of both parameters

\begin{tabular}{|c|c|c|c|c|c|c|c|}
\hline & \multicolumn{3}{|c|}{ Lengthwise measurements $(l)$} & & \multicolumn{3}{|c|}{ Perpendicular measurements $(p)$} \\
\hline & $\mathrm{B}$ & DF & $p$ value & & $\mathrm{B}$ & DF & $p$ value \\
\hline A & 37.373 & 3.0048 & $<0.001$ & A & 44.511 & 3.1380 & $<0.001$ \\
\hline $\mathrm{T}$ & 6.0428 & 5.219 & $<0.001$ & $\mathrm{~T}$ & 5.1808 & 4.9380 & $<0.001$ \\
\hline AT & 4.0725 & 13.569 & $<0.001$ & AT & 6.2715 & 12.293 & $<0.001$ \\
\hline
\end{tabular}


Table 3 Nonparametric analysis of colourimetric changes $(\Delta E)$ analysing the differences between the measurement points M2-M8 and only comparing M2 and $\mathrm{M} 8$

$A$ effect of test group, $T$ effect of measurement point, $A T$ interaction of both parameters

\begin{tabular}{|c|c|c|c|c|c|c|c|}
\hline & \multicolumn{3}{|c|}{$\Delta E \mathrm{M} 2-\mathrm{M} 8$} & & \multicolumn{3}{|c|}{$\Delta E \mathrm{M} 2$ vs $\mathrm{M} 8$} \\
\hline & B & $\mathrm{DF}$ & $p$ value & & $\mathrm{B}$ & $\mathrm{DF}$ & $p$ value \\
\hline A & 7.4458 & 3.6404 & $<0.001$ & A & 0.25722 & 3.9007 & 0.90148 \\
\hline $\mathrm{T}$ & 52.919 & 3.9267 & $<0.001$ & $\mathrm{~T}$ & 37.843 & 1.000 & $<0.001$ \\
\hline AT & 2.5834 & 13.250 & 0.0012 & AT & 0.32862 & 3.8243 & 0.85087 \\
\hline
\end{tabular}

compared to M4 was around $4 \mathrm{U}$ for GP, $\mathrm{HB}$ and MP, $3 \mathrm{U}$ for $\mathrm{BC}$ and nine for LT.

The second coffee immersion (M6) and toothbrushing (M7) showed similar behaviours in colour difference. However, LT showed a colour change after coffee immersion half as that by the first coffee immersion (M4). The third session of simulated toothbrushing (M8) caused no further significant colour change in all the tested groups (Fig. 3).

The total final colour change $(\Delta E)$ of all polished groups was around 3.3-4.4 $\mathrm{U}$ as compared to M2. Analysing the differences in colourimetric changes between the M2 and M8 measurements, the colour change was statistically different, but no statistical differences between the test groups could be detected (Table 3).

If the single parameters $\mathrm{L}^{*}, \mathrm{a}^{*}, \mathrm{~b}^{*}$ were examined separately, it was seen that the final colour change of around $4 \mathrm{U}$ was basically dominated by the $\mathrm{L}^{*}$ and $\mathrm{a}^{*}$ values. The lightness $\mathrm{L}^{*}$ decreased slightly after application of the sealant, remained almost constant during the thermocycling process (except in the HB group), then showed a distinctive dropping after coffee staining and increasing, attaining partly reversible values, after toothbrushing (Fig. 4a).

The $\mathrm{a}^{*}$ value (red-green) increased constantly after polishing procedure (M2) and thermocycling (M3). It increased after coffee staining (M4, M6) and partly decreased after simulated toothbrushing (M5, M7, M8). The a* value increased slightly more in the LT and MP groups, but less with the BC, GP and HB treatments (Fig. 4b).
The $b^{*}$ parameter (yellow-blue) did not seem to be influenced by the polishing procedure or the thermocycling. It increased slightly after coffee staining but finally reached its initial values after simulated toothbrushing (Fig. 4c).

\section{SEM analysis}

Qualitative SEM analysis showed four different ageing patterns regarding the test groups. LT and GP showed a similar behaviour in the ageing processes. The surface showed only slight alterations until the first toothbrushing (M5). Some debondings at the restoration margin occurred and a slight wear pattern due to toothbrushing simulation was detectable. Further toothbrushing simulation (M7, M8) increased this wear pattern, exhibiting the unpolished composite surface (Fig. 5a). After the final ageing procedure (M8), more than $70 \%$ of the composite surface was uncovered (Fig. 5b). BC was more susceptible to thermocycling than the other groups. At measurement point M3, a distinguished crack pattern was detectable on the surface. Some first partial debondings were also found. Further ageing procedures led to further crack propagation and more debonding (Fig. 5c). However, the wear pattern due to toothbrush abrasion found in LT and GP was not prominent in BC. HB had some difficulties after the entire surface was wetted, so there were some uncoated areas from the beginning in this condition. The wear pattern showed a rather superficial alteration, including some wear grooves from toothbrushing. However, the wear effect of toothbrushing was never prominent enough to reveal uncovered
Fig. 3 Colourimetric mean changes $(\Delta \mathrm{E})$ during measurements M2-M8 always referred to the initial polish M2

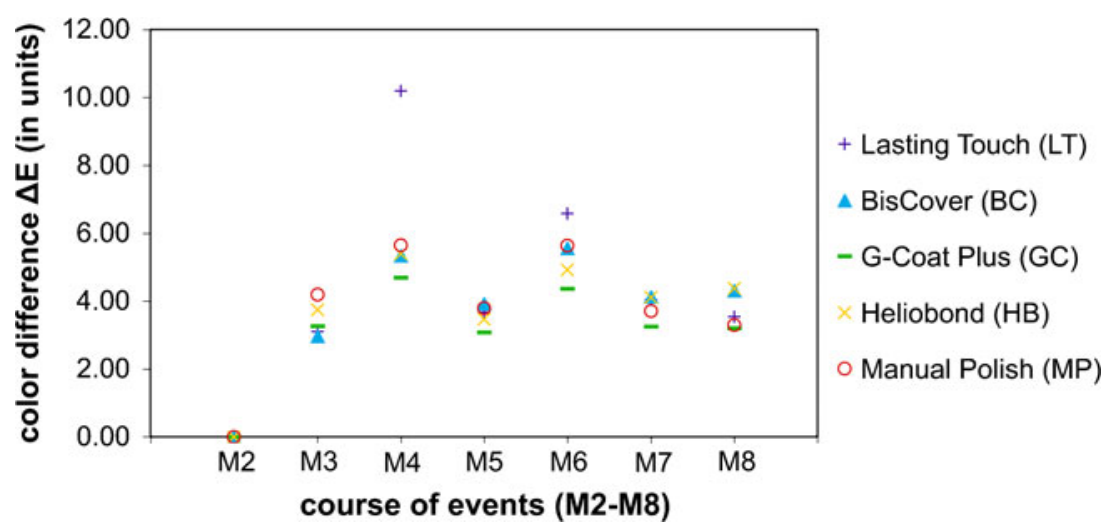


Fig. 4 a Colourimetric changes in $\mathrm{L}^{*}$ over all measurements (M1-M8). b Colourimetric changes $\mathrm{a}^{*}$ over all measurements (M1-M8). c Colourimetric changes $b^{*}$ over all measurements (M1-M8) a

$\stackrel{\frac{0}{3}}{\frac{7}{3}}$

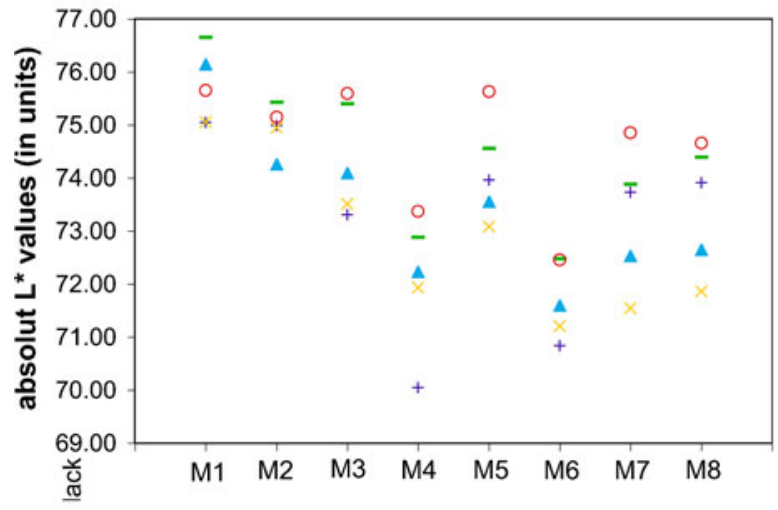

+ Lasting Touch (LT)

$\triangle \mathrm{BisCover}(\mathrm{BC})$

- G-Coat Plus (GC)

Heliobond (HB)

- Manual Polish (MP)

b

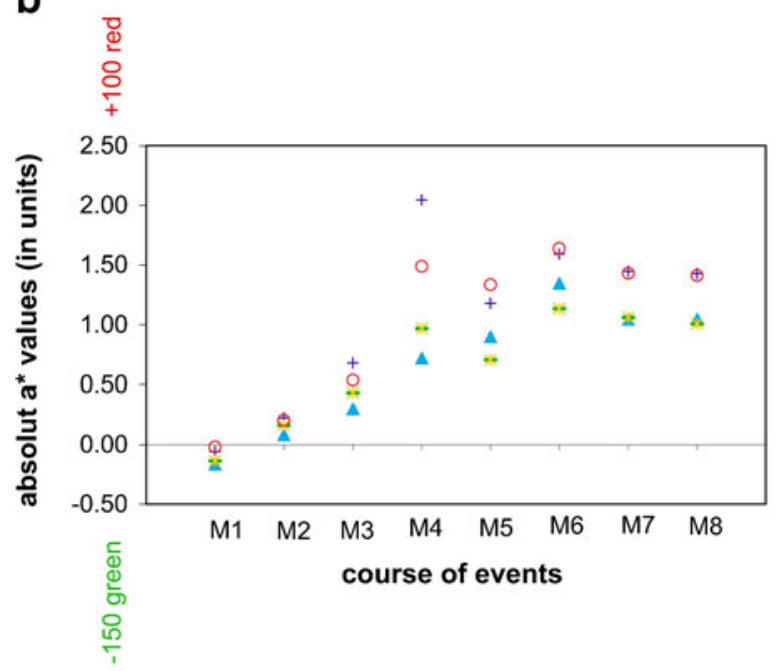

+ Lasting Touch (LT)

$\triangle \mathrm{Bis}$ Cover $(\mathrm{BC})$

- G-Coat Plus (GC)

$\times$ Heliobond (HB)

- Manual Polish (MP)

C

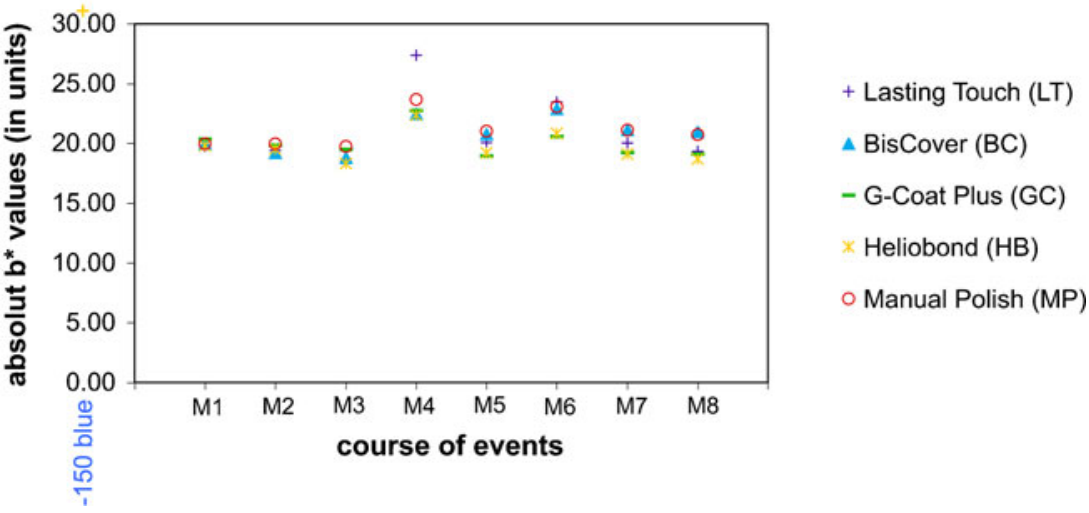

composite surfaces (Fig. 5d). In MP there were hardly any surface alterations detectable at lower magnification $(\times 17)$ (Fig. 5e). However, at a higher magnification, the ageing procedure tended to expose filler particles at the surface.
There was no groove pattern visible due to the tooth brushing procedure. Overall, the surface of manually polished specimens was the most stable with regard to qualitative SEM analysis. 
Fig. 5 SEM photomicrographs of one surface of each group (magnification, $\times 17$ ) at the end of the ageing procedure (M8). a The sealant-coated surface (LT) shows a strong wear pattern exposing the underlying composite restoration $(C R)$. Almost the entire coating is abraded at the end of the artificial ageing. $T S$ tooth surface. b The wear pattern observable in GP on the surface is similar to $L T$; the surface coating $(G P)$ is lost in a lamellar form, exposing the composite restoration $(C R)$. The restoration margin $(R M)$ is clearly detectable. c The brittle structure of the surface coating $(B C)$ with a lot of cracks (less then symbol) is visible. The composite surface $(C R)$ is visible over large areas. TS tooth surface. d A debonding of $H B$ is detectable at the margin of the restoration exposing the rough composite restoration $(C R)$. Furthermore, some voids (asterisks) are visible on the surface. TS tooth surface. e The composite restoration $(C R)$ in the MP group shows a uniform surface texture.

The restoration margin $(R M)$ is clearly detectable. TS tooth surface
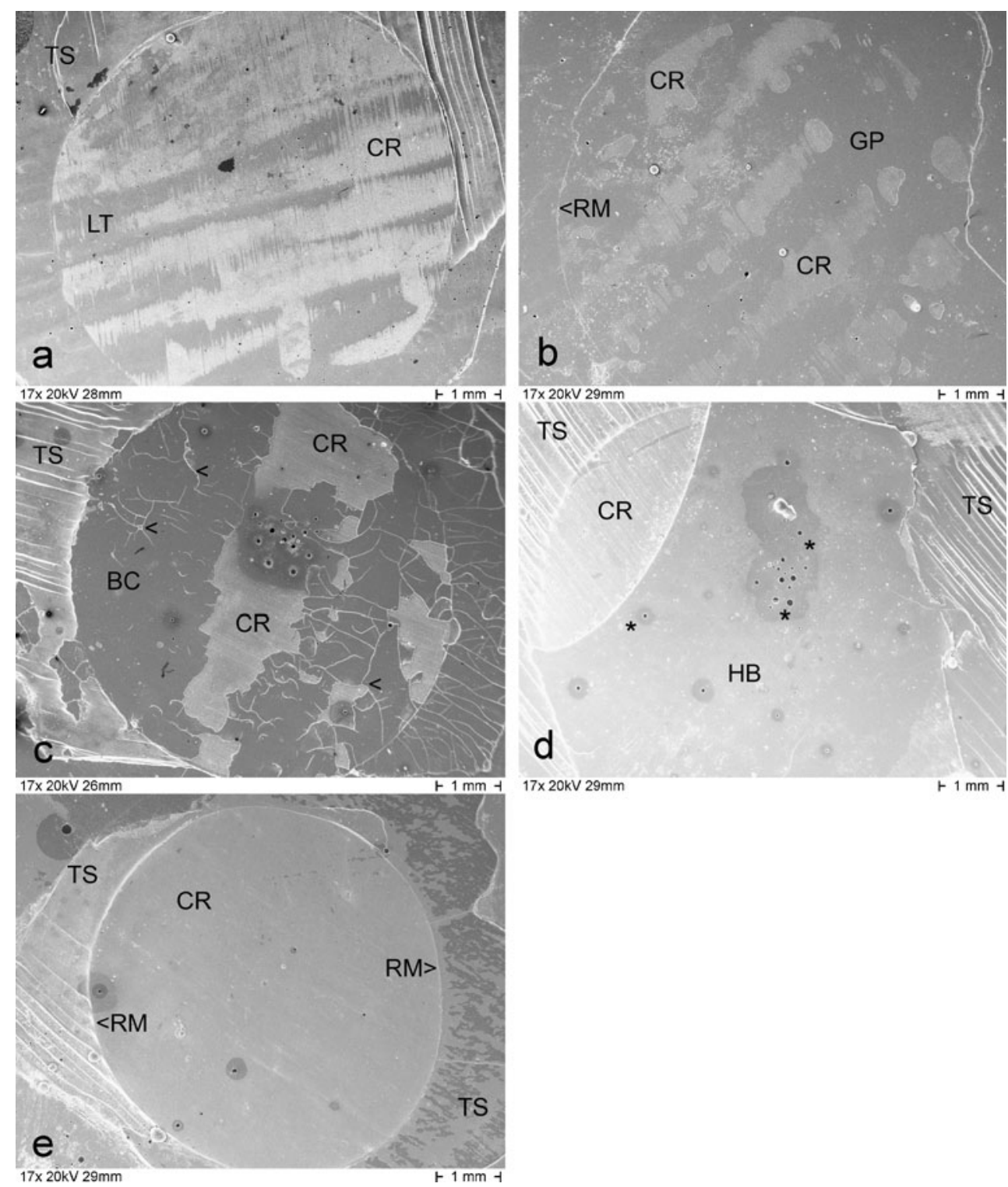

\section{Discussion}

In the present study, surface sealants had the potential to smoothen rough surfaces without previous polishing. Those findings are in agreement with other studies [13, 27]. However, the behaviour of surface sealants regarding different ageing procedures has not been systematically evaluated until now.

\section{Surface roughness}

The difference of the lengthwise and perpendicular measurements at baseline was a side effect and occurred due to the fact that the circular movements of the automatic grinding machine left long visible falciform grooves that appeared on the small surface of the composite restoration as nearly straight grooves. However, this effect allowed to analyse if sealants can compensate those macro irregularities. It was shown that the differences in the two measurement orientations were most visible in LT and BC. When applying these two surface sealants, it would be recommended to first use a fine grinding polisher. On one hand, a thin surface sealant layer is desirable, since a thick layer decreases microhardness [11] and could lead to occlusal interferences. On the other hand, too thin a layer can barely even out surface irregularities or defects of insufficiently polished composite restorations. Other studies have already reported that surface sealants could not compensate the surface irregularities from treatments as well as conventional polishing procedures $[10$, 20]. Therefore, some studies recommend a combination of polishing and sealing $[12,21]$. It was reported that sealants in general had little effect on a previously, conventionally polished surface [20]. Other studies proved that it is difficult to obtain a regular surface with liquid resins $[11,21]$. 
The simulated brushing procedure did not have a roughening or a smoothening effect on BC, GP, HB and MP. Only after the first and second 20,000 brushing strokes was a smoothening effect detected on LT, levelling out the longitudinal and perpendicular discrepancy. The increase in roughness for LT after the last 40,000 brushstrokes may be explained by the higher wear and partial loss of the sealant, revealing the characteristics of the underlying composite. This is partly in contrast to a recently published study that found a smoothening effect after toothbrushing application in all specimens [13]. However, in the aforementioned study, the composite restoration was well polished before the surface sealant was applied. Furthermore, the toothbrushing procedure was increased (100,000 to 200,000 strokes), so that in the end complete sealant removal was observed.

Further studies could be performed to investigate the effect of different toothbrushes and toothpastes on a sealant surface, since prior studies on composite have observed that the toothpaste has a significant influence on the surface roughness $[28,29]$. Furthermore, the composition of the composite itself is of importance with regard to the susceptibility to toothbrush wear $[30,31]$. This was also detectable regarding the surface sealants, as some of them were very stable regarding wear (HB), whereas others seemed to be less resistant and "brushed away" after the ageing procedure (LT and GP).

However, toothbrushing is not the only way to simulate wear, but was chosen in the present study as all three measuring parameters (wear, colourimetric evaluations and SEM analysis) were analysed on the same specimen, and therefore an equal distribution of the wear pattern on the specimen surface was needed. It would also be of interest to study the effect of chewing simulation.

\section{Colourimetric evaluation}

Extrinsic factors, such as food, are known to cause staining of restorations [32-34]. To enhance the staining process, a clinically relevant pellicle-like layer was created by immersing the specimens in saliva prior to coffee treatment. The spectrometer Easyshade was chosen for the colour measurements in this study. Although there seems to be a significant disagreement of measurement devices with human colour perception [35], it was shown that the Easyshade spectrometer was the most reliable and precise tooth colour-measuring instrument for both in vitro and in vivo applications [36]. The CIE $\mathrm{L}^{*} \mathrm{a} * \mathrm{~b} *$ system allowed to describe small colour differences [37]. Although $\Delta E$ itself does not absolutely assess the colour change since the value is always positive, it is of importance as there is a threshold value of perception for the human eye. Although $\Delta E$ values between 1.0 and 3.7 are visually detectable [38-40], studies have shown that $\Delta E$ values of 2.72 to 6.8 are acceptable for dental restorations [40-42]. In all groups, even the polishing procedure and the thermocycling resulted in colour changes big enough to be detected by the human eye.

Quantitative comparisons can be made by use of the absolute colour parameters $\mathrm{L}^{*}, \mathrm{a}^{*}$ and $\mathrm{b}^{*}$. When analysing the colour parameters, the lightness $\left(\mathrm{L}^{*}\right)$ decreased in $\mathrm{BC}$, GP and slightly in MP after the polishing procedure, while the red-green colour balance $\left(\mathrm{a}^{*}\right)$ was slightly shifted in favour of red in all groups. A decrease in lightness after the application of $\mathrm{BC}$ was also reported elsewhere [33]. The thermocycling had a decreasing lightness influence on LT and $\mathrm{HB}$, while the red-green colour balance for these two materials was again slightly shifted in favour of red in all groups. In an earlier study, temperature changes were shown to affect unfilled resins more adversely than they affected filled resin [43]. This could not be shown in this study. No difference in $\Delta E$ was found among the surfacesealed groups and the manually polished.

The simulated toothbrushing had a partly reversible influence and showed reverse $L^{*}, a^{*}$ and $b^{*}$ parameters. This indicates that coffee stains are mainly extrinsic and can be partially brushed off. The amount of colour change $\Delta E$ caused by the second coffee staining was close to but not as high as $\Delta E$ of the first staining in all groups.

The higher staining of LT might be correlated with its surface roughness, which was the highest among the surface sealants. The first simulated toothbrushing seemed to have a positive smoothening influence on LT, which might explain the less increased staining in the second toothbrushing treatment. Furthermore, toothbrushing could have abraded the outer oxygen-inhibited surface layer of the resin, which might be more susceptible to extrinisic staining [44]. The third brushing treatment showed only a small influence on the colour that was even less than the application of the sealant and thermocycling.

The $b^{*}$ value remained almost constant. This observation partly contradicts the finding of Lee and Lee [45], who also investigated the colour effect of thermocycling $(\times 5,000)$ on various resin composites. Although the colour change was in the similar range of $\Delta E=1.1-4.6$, they stated that the colour difference was mainly influenced by an increasing $b^{*}$ value (yellow direction) and a decreasing $\mathrm{L}^{*}$ value. However, comparing just the composite CeramX M2, very similar results to the present study were found [45].

\section{SEM analysis}

The roughness measurements were performed only on central surface parts and represent the microstructure of the sealant. The roughness measurements did not provide information about the macrostructure of wear, such as chipping, abrasion or spalling of the surface sealant during the procedures. Such information was observed by SEM analysis. 
Some of the GP-coated surfaces started to detach shortly after application. These surfaces seemed to be very sensitive to dryness, which was partially unavoidable during colour and roughness measurements. HB achieved the lowest Ra values. However, it had a tendency to form pools and not adequately cover the coated surface during application. Therefore, the sealant layer became inhomogeneous. Difficulties in wettability were reported in previous studies and might be explained by the varying surface tension of the liquid surface sealant and the solid composite and contamination with moisture $[9,20]$.

Importantly, increased wear could be observed from simulated brushing. The abrasion pattern caused by the simulated brushing after 80,000 strokes often showed long spots perpendicular to the brushing stroke, where the sealant had initially been slightly thicker due to the horizontal movement of the application. HB started to detach and chip on the edges, perhaps due to tension differences between the HB liquid and the surface underneath. Nevertheless, each small debonding and chipping leads to new unwanted margins that might consequently lead to bacterial retention. Recently, it was shown, that copolymerising surface sealants with the underlying composite decreased retention loss of the coatings [13].

Surface sealants would be of interest for covering restorations in anterior teeth, where aesthetics are of high importance. The application of surface sealants would be time saving as compared to multi-step polishing procedures and guarantee a lustrous aspect of the restorations. However, as revealed in this study, surface sealants tend to debond and degrade. Although yearly recoating has been suggested in other studies $[22,46]$, it seems to be unrealistic to perform. As already concluded by other researchers, application of a sealant results in additional costs for both the clinician and the patient [10]. Furthermore, tidy handling is not always easy to achieve and the proper application of a sealant, including etching, dwelling time and light curing, will not save time in the polishing process.

Furthermore, the long-term adhesion of the sealant on the composite surface is questionable. Therefore, a conventional mechanical polish is preferable and strongly recommended for permanent composite restorations. For the polish of a provisional restoration, application of a surface sealant could be considered.

The working hypotheses had to be rejected:

Hypothesis 1: There were significant differences between the analysed test groups regarding surface roughness after initial application.

Hypothesis 2: Toothbrush abrasion significantly influenced the roughness in all test groups.

Hypothesis 3: Significant differences in staining susceptibility were measured between the groups during the ageing procedure. However, at the end, all groups exhibited a similar but significant different colour change compared to the time of initial sealant application.

Acknowledgements The authors are indebted to Ivoclar Vivadent for the adhesive material and the light curing unit, to Dentsply DeTrey for the surface sealant and the composite material. Special thanks to Mr. Iff, School of Dental Medicine, University of Bern for drawing Fig. 1. Finally, the authors thank Prof. A. Peutzfeldt for reviewing the manuscript.

Conflict of interest There are no conflicts of interest.

\section{References}

1. Weitman RT, Eames WB (1975) Plaque accumulation on composite surfaces after various finishing procedures. J Am Dent Assoc 91:101-106

2. Ikeda M, Matin K, Nikaido T, Foxton RM, Tagami J (2007) Effect of surface adherence of $\mathrm{S}$. mutans to indirect resin composites. Dent Mater J 26:915-923

3. de Fucio SB, Puppin-Rontani RM, de Carvalho FG, MattosGraner Rde O, Correr-Sobrinho L, Garcia-Godoy F (2009) Analyses of biofilms accumulated on dental restorative materials. Am J Dent 22:131-136

4. Quirinen M, Bollen CM, Papaioannou W, Van Eldere J, Van Steenberghe D (1996) The influence of titanium abutment surface roughness on plaque accumulation and gingivitis: short-term observations. Int J Oral Maxillofac Implants 11:169-178

5. Bollen CM, Lambrechts P, Quirynen M (1997) Comparison of surface roughness of oral hard materials to the threshold surface roughness for bacterial plaque retention: a review of the literature. Dent Mater 13:258-269

6. Jones CS, Billington RW, Pearson GJ (2004) The in vivo perception of roughness of restorations. Br Dent J 196:42-45

7. Lu H, Roeder LB, Lei L, Powers JM (2005) Effect of surface roughness on stain resistance of dental resin composites. J Esthet Restor Dent 17:102-108

8. Davidi MP, Beyth N, Sterer N, Feuerstein O, Weiss EI (2007) Effect of liquid-polish coating on in vivo biofilm accumulation on provisional restorations: part 1. Quintessence Int 38:591-596

9. Tjan AH, Tan DE (1991) Microleakage at gingival margins of class $\mathrm{V}$ composite resin restorations rebonded with various lowviscosity resin systems. Quintessence Int 22:565-573

10. Takeuchi CY, Orbegoso Flores VH, Palma Dibb RG, Panzeri H, Lara EH, Dinelli W (2003) Assessing the surface roughness of a posterior resin composite: effect of surface sealing. Oper Dent 28:281-286

11. Bertrand MF, Leforestier E, Muller M, Lupi-Pégurier L, Bolla M (2000) Effect of surface penetrating sealant on surface texture and microhardness of composite resins. J Biomed Mater Res 53:658-663

12. Sarac D, Sarac YS, Kulunk S, Ural C, Kulunk T (2006) The effect of polishing techniques on the surface roughness and color change of composite resins. J Prosthet Dent 96:33-40

13. Cilli R, de Mattos MC, Honorio HM, Rios D, de Araujo PA, Prakki A (2009) The role of surface sealants in the roughness of composites after a simulated toothbrushing test. J Dent 37:970-977

14. Attar N (2007) The effect of finishing and polishing procedures on the surface roughness of composite resin material. J Contemp Dent Pract 8:27-35 
15. Prakki A, Ribeiro IW, Cilli R, Mondelli RF (2005) Assessing the tooth-restoration interface wear resistance of two cementation techniques: effect of a surface sealant. Oper Dent 30:739746

16. Kawai K, Leinfelder KF (1995) Effect of resin composite adhesion on marginal degradation. Dent Mater J 14:211-220

17. Doray PG, Eldiwany MS, Powers JM (2003) Effect of resin surface sealers on improvement of stain resistance for a composite provisional material. J Esthet Restor Dent 15:244-250

18. Lee YK, Lu H, Powers JM (2005) Effect of surface sealant and staining on the fluorescence of resin composites. J Prosthet Dent 93:260-266

19. Owens BM, Johnson WW (2006) Effect of new generation surface sealants on the marginal permeability of class $\mathrm{V}$ resin composite restorations. Oper Dent 31:481-488

20. Roeder LB, Tate WH, Powers JM (2000) Effect of finishing and polishing procedures on the surface roughness of packable composites. Oper Dent 25:534-543

21. dos Santos PH, Pavan S, Consani S, Sobrinho LC, Sinhoreti MA, Filho JN (2007) In vitro evaluation of surface roughness of 4 resin composites after the toothbrushing process and methods to recover superficial smoothness. Quintessence Int 38:e247-e253

22. Dickinson GL, Leinfelder KF (1993) Assessing the long-term effect of a surface penetrating sealant. J Am Dent Assoc 124:68-72

23. Reid JS, Saunders WP, Chen YY (1991) The effect of bonding agent and fissure sealant on microleakage of composite resin restorations. Quintessence Int 22:295-298

24. C.I.E. Commission Internationale de l'Eclairage (1978) Recommondations on uniform color spaces, color difference equations, psychometric color terms, supplement No. 2 of publication CIE No. 1 (E-1.3.1). Bureau Central de la CIE, Paris

25. Newby CS, Creeth JE, Rees GD, Schemenhorn BR (2006) Surface microhardness changes, enamel fluoride uptake, and fluoride availability from commercial toothpastes. J Clin Dent 17:94-99

26. Brunner E, Domhof S, Langer F (2002) Nonparametric analysis of longitudinal data in factorial designs. Wiley, New York

27. Perez CR, Hirata R Jr, Silva AHMFT, Sampaio EM, Miranda MS (2009) Effect of a glaze/composite sealant on the 3-D surface roughness of esthetic restrative materials. Oper Dent 34:674-680

28. Goldstein GR, Lerner T (1991) The effect of toothbrushing on a hybrid composite resin. J Prosthet Dent 66:498-500

29. McCabe JF, Molyvda S, Rolland SL, Rusby S, Carrick TE (2002) Two- and tree-body wear of dental restorative materials. Int Dent J $52: 406-416$
30. Heintze SD, Forjanic M (2005) Surface roughness of different dental materials before and after simulated toothbrushing in vitro. Oper Dent 30:617-626

31. Heintze SD, Forjanic M, Ohmiti K, Rousson V (2010) Surface deterioration of dental materials after simulated toothbrushing in relation to brushing time and load. Dent Mater 26:306-319

32. Guler AU, Yilmaz F, Kulunk T, Guler E, Kurt S (2005) Effects of different drinks on stainability of resin composite provisional restorative materials. J Prosthet Dent 94:118-124

33. Lee YK, Powers KM (2007) Combined effects of staining substances on resin composites before and after surface sealant application. J Mater Sci Mater Med 18:685-691

34. Soares LE, Cesar IC, Santos CG, De Cardoso AL, Liporoni PC, Munin E, Martin AA (2007) Influence of coffee on reflectance and chemistry of resin composite protected by surface sealant. Am J Dent 20:299-304

35. Burkhard H, Witzel T, Klaiber B (2005) Comparison of in vivo visual and computer-aided tooth shade determination. Clin Oral Investig 9:244-250

36. Dozić A, Kleverlaan CJ, El-Zohairy A, Feilzer AJ, Khashayar G (2007) Performance of five commercially available tooth colormeasuring devices. J Prosthodont 16:93-100

37. Khokhar ZA, Razzoog ME, Yaman P (1991) Color stability of restorative resin. Quintessence Int 22:733-737

38. Kuehni RG, Marcus RT (1979) An experiment in visual scaling of small color differences. Color Res Appl 4:83-91

39. Seghi RR, Hewlett ER, Kim J (1989) Visual and instrumental colorimetric assessments of small color differences in translucent dental porcelain. J Dent Res 68:1760-1764

40. Johnston WM, Kao EC (1989) Assessment of appearance match by visual observation and clinical colorimetry. J Dent Res 68:819-822

41. Ruyter IE, Nilner K, Moller B (1987) Color stability of dental composite resin materials for crown and bridge veneers. Dent Mater 3:246-251

42. Ragain JC Jr, Johnston WM (2000) Color acceptance of direct dental restorative materials by human observers. Color Res Appl 25:278-285

43. Asmussen E (1974) The effect of temperature changes on adaptation of resin fillings. Acta Odontol Scand 32:291-297

44. Janda R, Roulet JF, Latta M, Kaminsky M, Rüttermann S (2007) Effect of exponential polymerization on color stability of resin based filling materials. Dent Mater 23:696-704

45. Lee SH, Lee YK (2008) Effect of thermocycling on optical parameters of resin composites by the brand and shade. Am J Dent 21:261-367

46. Dickinson GL, Leinfelder KF, Mazer RB, Russell CM (1990) Effect of surface penetrating sealant on wear rate of posterior composite resins. J Am Dent Assoc 121:251-255 